\title{
Enhancement of WEEE Management Practices in MTN Phone Village, Rumukurushi, Port Harcourt, Nigeria
}

\author{
Ogechukwu Okwu ${ }^{1, *}$, Andrew Hursthouse ${ }^{1}{ }^{\mathbb{D}}$, Evi Viza $^{1}$ and Linus Idoko ${ }^{2}$ \\ 1 School of Computing, Engineering \& Physical Sciences, University of the West of Scotland, \\ Paisley PA1 2BE, Scotland, UK; andrew.hursthouse@uws.ac.uk (A.H.); evi.viza@uws.ac.uk (E.V.) \\ 2 Department of Electronic \& Computer Engineering, Veritas University, Bwari, Abuja 900001, Nigeria; \\ idokol@veritas.edu.ng \\ * Correspondence: ogechukwu.okwu@uws.ac.uk
}

check for updates

Citation: Okwu, O.; Hursthouse, A.; Viza, E.; Idoko, L. Enhancement of WEEE Management Practices in MTN Phone Village, Rumukurushi, Port Harcourt, Nigeria. Recycling 2021, 6, 77. https://doi.org/10.3390/ recycling6040077

Academic Editor: Akira Otsuki

Received: 23 September 2021 Accepted: 19 November 2021 Published: 24 November 2021

Publisher's Note: MDPI stays neutral with regard to jurisdictional claims in published maps and institutional affiliations.

Copyright: (c) 2021 by the authors. Licensee MDPI, Basel, Switzerland. This article is an open access article distributed under the terms and conditions of the Creative Commons Attribution (CC BY) license (https:// creativecommons.org/licenses/by/ $4.0 /)$.

\begin{abstract}
Informal recycling has been a source of challenges to a mobile telephone network (MTN) phone village in Rumukurushi, Port Harcourt, Nigeria, and several locations in developing countries. In order to bring a lasting solution to the menace of informal recycling in this location, the study proposed a new waste electrical and electronic equipment (WEEE) management system. The system comprises the application of two key concepts. The first concept includes limiting the activities of informal recyclers to WEEE collection only. This implies WEEE treatment, dismantling, etc., are carried out by government-approved agencies and experts. The second concept involves the application of the just-in-time (JIT) management concept for managing WEEE. The concept ensures that WEEE is only requested from the recycler or the individuals in possession of it and only on demand. The study adopted a qualitative research approach. Data collection and analysis were achieved via semi-structured phone interviews and thematic analysis, respectively. The outcome of the study limits the activities of the informal recyclers to WEEE collection. Informal recyclers gain revenue from collection. A reduction in the waiting time of workers and WEEE storage space is achieved. This offers safety, efficiency, and an increased productivity. This will help to revolutionise the WEEE management system in the location.
\end{abstract}

Keywords: informal recycler; WEEE management; hazard; collection

\section{Introduction}

The quest to achieve monetary gains from the oil and gas sector in Nigeria necessitated the influx of individuals into the city of Port Harcourt, Nigeria. An MTN phone village in this context implies an area where the sales, maintenance, and repairs of mobile phones take place. Due to the continuous increase in inhabitants experienced in the location, there is a steady increase in the population, WEEE, and material consumption, alongside other contaminants that can affect the environment. This creates room for a continuous rise in the quantity of WEEE produced in the location [1]. The study location's mobile telephone network (MTN) phone village, Rumukurushi, is faced with the challenge of informal recycling. It is believed that a total of approximately thirty informal recyclers carry out their recycling activities in the location. Informal recycling is the main WEEE practice in the location [2]. The informal recyclers in the location lack awareness of accessible protection, as well as their rights. They engage in an unsafe WEEE management technique, hence exposing both themselves and individuals in the location, as well as the environment, to risk [3].

The inappropriate disposal of WEEE and other forms of waste is typical of developing countries; for example, Nigeria [4]. The consequences of conveying waste electrical and electronic waste, WEEE, across the African borders are no longer hidden, as the location appears to be the choice location for dumping e-waste. As such, it has emerged as an issue of great concern to those involved with policymaking in the location [5]. WEEE is a 
prevailing and growing challenge globally, with an estimated value of more than 50 million metric tons annually generated [6]. Waste electrical and electronic equipment, WEEE, comprises components and devices with the potential to bring about serious environmental harm due to their hazardous contents [7]. Mercury, an element found in WEEE, is a great source of pollution according to Erhardt et al. [8]. The management of WEEE is of key necessity, according to a study by Aidonis et al. [9], and this is because it: (i) forms a segment of solid waste that is always increasing, and (2) contains scarce, valuable, and hazardous elements.

Conversely, in Rai [10], WEEE is diverse in nature and comprises several systems that contain various classes of ceramics, plastics, and metals; hence, they are referred to as secondary sources of raw materials. There are some advantages associated with the recovery of WEEE, and these are the reduction in the consumption of energy, or saving in terms of the usage of virgin materials: raw material preservation [11]. Herat [12] created an awareness of WEEE not only implying challenges, as it also presents us with the opportunity to extract valuable materials. For instance, despite the numerous challenges associated with WEEE management, research has shown that there is a possibility to generate energy from the landfill, which is achieved either through thermal treatment or methane extraction. The potential to generate energy is faced with a lack of experienced professionals as its key limitation [13]. A study has also demonstrated that, when WEEE is properly managed, it facilitates the attainment of economic, social, and environmental benefits [14]. WEEE serves as a source of important raw materials; for example, gold. It comprises a considerable amount of critical precious metals. Besides the presence of toxic elements and base metals, it also contains rare earth elements. The desire to recover precious metals has been identified as one of the major reasons for recycling WEEE [15-17]. In [18], rare earth elements, such as neodymium, lanthanum, yttrium, and cerium, among others, are also present in WEEE. A study has shown that gold can also be recovered from waste light-emitting diodes, LEDs [19]. Mobile phone printed circuit boards contain elements such as lead $(\mathrm{Pb})$, nickel $(\mathrm{Ni})$, silver $(\mathrm{Ag})$, gold $(\mathrm{Au})$, tin $(\mathrm{Sn})$, and copper $(\mathrm{Cu})[20,21]$. Indium, for instance, can be recovered from LCD panels [22].

Unlike developing countries that are presently faced with economic challengesfor example, poverty - developed nations have the required technology, finance, and other important facilities, yet they export their WEEE into developing nations, as it is the cheapest option [23]. Informal recycling exposes both human life and the environment to substances that are toxic, as the emission system is not under any form of control $[24,25]$. WEEE comprises several hazardous substances, such as refractory oxides, plastics, and metals [26,27]. Informal WEEE recyclers, as well as their family members, are at risk of exposure to toxic elements. This is because their nature of activities exposes them and the surrounding area to polychlorinated biphenyls, flame retardants, mercury, lead, cadmium, etc. Some of the components in WEEE that constitute hazards include mercury-containing devices, circuit boards, batteries, liquid crystal display (LCD) televisions, and cathoderay tubes [28-30]. Children who reside in WEEE recycling locations are also exposed to health risks due to the exposure to dust particles containing trace elements [31]. Several threats to life and the environment are associated with WEEE recycling, and its mitigation requires an approach that is sustainable [32]. The concentration of bacteria rises during the rainy season; hence, it affects life and the environment negatively [33]. Individuals from low-income families tend to live close to pollution and are likely to suffer more [34]. The projected volume of WEEE generated globally rose to 49.8 metric tons in 2018 [35], as shown in Figure 1.

In Jaiswal et al. [36], some of the factors that facilitate the ever-increasing volume of WEEE are as follows: (a) the rapid growth without restriction of the electronic and "Information Technology" sector; (b) the production of electrical and electronic equipment with a shorter lifecycle, which tends to make the devices outdated within a short time; (c) the end user's shortage of ideas on what next to do with the WEEE scrap; (d) there is no generally accepted procedure for the management of WEEE; (e) a reduction in the 
product cost creates room for more devices to be bought, which implies more WEEE; (f) the re-usability and recycling rate are limited; (g) "Multifaceted processes of WEEE handling"; (h) the speedy technological innovation has made useable items old-fashioned; (i) items, such as plastics, that are non-degradable gained patronage due to their low cost, but expose the environment to risk; (j) the tendency of some consumers to use and discard makes it difficult for some products to be re-used. Besides, in Fang [37], there is no mandatory policy that makes it compulsory for waste to be cleaned up by those who created it.

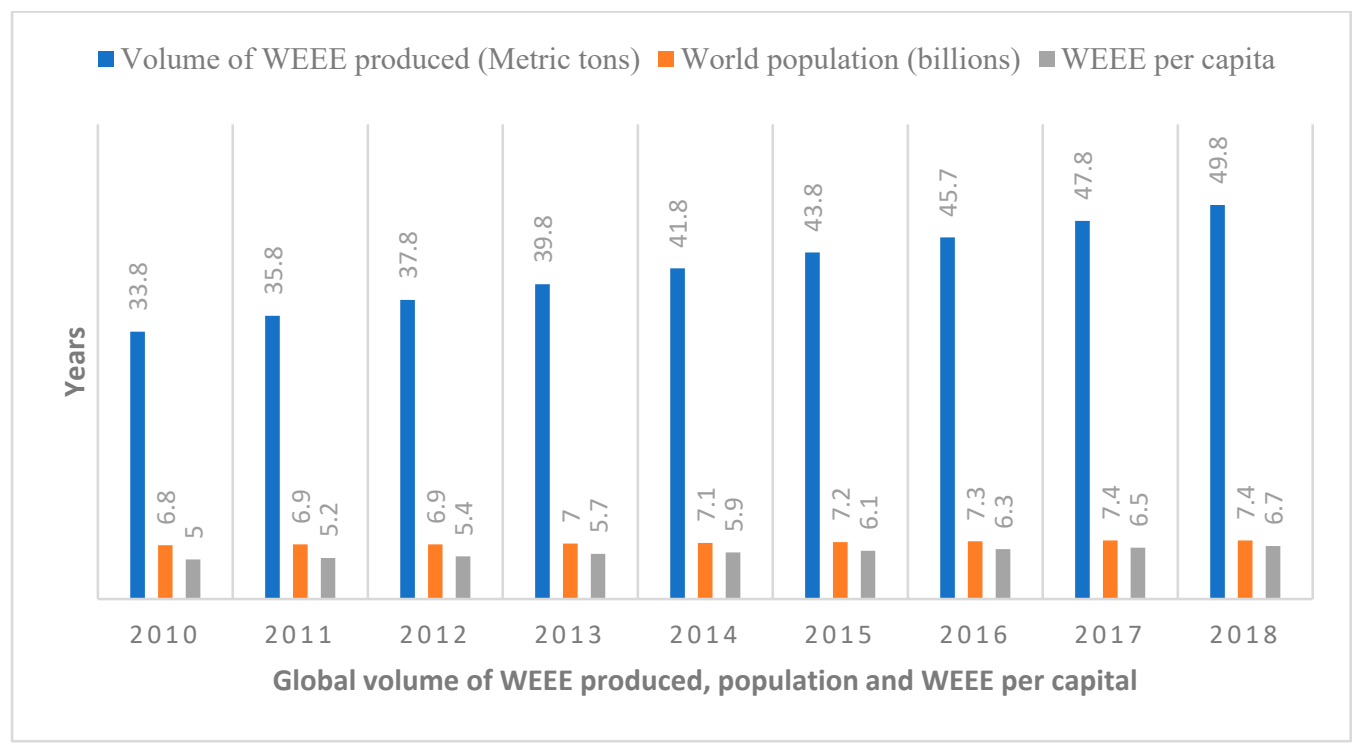

Figure 1. The projected amount of WEEE generated globally per year, population, and WEEE per capita.

In Lawal [38], several pieces of land in Nigeria that would have been put to good use are currently being used as WEEE dumpsites. The main concern with WEEE management is the processes involved in its treatment, which presents risk to the environment as well as to "human health". The informally recyclers that are involved in the WEEE management lack appropriate training for the task and are ignorant of the health and environmental consequences of the business [39,40] (p. 11) [41,42]. The health and environmental impacts of the release of hazardous elements are not easy to identify by those involved [43]. Stopping the unlawful importation of WEEE into the country is not enough to put an end to the challenges associated with WEEE management. WEEE generated domestically has to be properly managed [44]. Ndunda and Ambole [42] (p. 77), opined that recyclers are not adopting formal recycling techniques, and that one of the reasons is because it is expensive. The study recommends that the government should ensure the strict compliance of the "producer responsibility" for the proper management of WEEE.

One of the factors that have also contributed to WEEE generation is that there is no international legal agreement on the management of WEEE [41]. Furthermore, the creation of public awareness on the need to put in place a good policy for managing toxic or hazardous elements is of great importance, but is yet to be adopted by the stakeholders [45]. Most developing countries are unable to practice informal recycling because they lack the right facilities to manage WEEE. The study recommends that the highest accepted method to manage WEEE is the "extended producer responsibility" [46,47]. Nigeria is a good example of a country with deficiencies in the management of WEEE [48]. In order to combat the challenges associated with WEEE management, a collective collaboration of formal recyclers, the government, business, and the social-economic sector is a necessity [40]. For WEEE to be properly managed, a strict policy has to be established [49]. 
The focus of this study is to reduce the role of the informal recyclers in WEEE management in order to completely tackle the challenges associated with their method of practice.

\subsection{A Review of Past Research Efforts to Manage WEEE}

Several attempts have been carried out in the past to tackle the challenges associated with informal recycling. Some of the attempts made to tackle the challenges previously are given below:

In Mihai et al. [48], an effort was made using statistical data on waste and thematic cartography in order to ascertain the geographical movement of WEEE at both national and global levels. The study considered the adopted style used for the management of WEEE in each of the geographical locations; for example, Africa, Oceania, South America, North America, Europe, etc. What was the outcome of the study? The findings show that a shortage of the required amenities is the reason for African's poor approach to WEEE management. How has the study addressed the challenges associated with informal recycling? The study was unable to proffer a solution to the challenge, and this is because the study focused on the indicators of poor WEEE management. An identification of an approach that may help to proffer a solution to informal recycling would have been helpful.

In Aidonis et al. [9], a methodology was developed to identify a WEEE management scheme that is optimal for finding an alternative way in which the management of WEEE can be integrated. The study utilised a binary linear programming model to enhance the effectiveness of a total of nine WEEE management options. Twelve performance criteria that cut across social, environmental, technical, and financial dimensions were considered. What was the outcome of the study? The outcome of the study shows that recycling WEEE mechanically alongside the export of WEEE residues is the most effective strategy. How has the study addressed the challenges associated with informal recycling? The study was unable to address the challenges, and this is because the approach on offer cannot proffer a solution to the numerous challenges associated with informal recycling. An approach that is capable of reducing the activities of informal recyclers would have been more useful.

In Ndunda and Ambole [42] (p. 73), an effort was made to tackle the challenges caused by the informal recycling of WEEE by creating "a product-service system" for its management. In this study, supporters of a move from product provision to the "provision of systems of products and services" were developed alongside the support of stakeholders in order to manage WEEE efficiently. The concept of dematerialisation was adopted in this study using the effort of the collaborations of the stakeholder; this prevents the informal recyclers or consumers from having possession of equipment after EOL. What was the outcome of the study? The findings of the study indicate that the success of the method depends on the combined effort of each of the stakeholders. How has the study addressed the challenges associated with informal recycling? The study did not proffer a solution to the challenge. This is because dematerialisation can only be achieved when there is a technological and structural change in the location, which appears to be lacking in the chosen research location. Adopting a concept that applies to developing countries would make more contributions to locations where informal recycling technique is prevalent.

In George et al. [50], an attempt was made to address the management of WEEE, with emphasis on households, by assessing the make-up of the electrical and electronic devices in the apartments of the individuals in the selected location and the manner in which they manage WEEE. A survey approach, with the help of questionnaires for data gathering, was adopted by the study. What was the outcome of the study? The outcome of the study shows that the electrical and electronic devices that dominate the most in the location of the study are mobile phones. Conversely, the result of the study shows that the location of the study engages a WEEE management approach that is not sustainable, as they do not recycle their WEEE, but prefer to keep them in the house or drop them in the waste bin. How has the study addressed the challenges associated with informal recycling? The study was unable to address the challenges, and this is because no effort was made to reduce the 
effort of informal recyclers. Only recommendations were offered by the study. Designing a concept that can effectively proffer a solution to at least one of the numerous challenges associated with informal recycling would be valuable.

In the works of Arya et al. [51], a study was carried out to help ascertain the extent of awareness of both the recyclers and the user (organisations, companies, and individuals) on the hazards caused by WEEE. The study utilised a survey approach for data gathering using questionnaires from three different stakeholders, namely: organisations, individuals, and those involved with WEEE recycling. The survey carried out in this study comprises 10 individuals involved in WEEE recycling and 25 individual users of electrical and electronic devices, as well as 35 organisations classed as users. What was the outcome of the study? The outcome shows that both the individuals and the organisational users do not know the dangers of the WEEE. They lack adequate knowledge of WEEE legislature, and there is no good channel for WEEE collection. Finally, the informal recycler who lacks knowledge of the dangers associated with WEEE does not use a safe approach with regard to disposal. How has the study addressed the challenges associated with informal recycling? The study was unable to address the challenges associated with informal recycling, and this is because the focus was on the extent of awareness of both the recyclers and the users. The researcher should have also suggested health and safety training as an alternative way to acquire awareness.

In a recent study by Ogbuanya and Afeez [49] (p. 90), the researchers shed light on how WEEE techniques adopted in the workshops of "electrical/electronic technicians" can be improved. The study adopted the use of questionnaires for data gathering, and the individuals involved comprise 54 officers in the "public health" sector and 87 lecturers from the faculty of engineering. The analysis of the data gathered was carried out with the help of percentage, mean, and standard deviation using t-test and ANOVA. What was the outcome of the study? The outcome of the study shows that provision of the "recycling site", introduction, and application of policies are the main techniques for WEEE management. How has the study addressed the challenges associated with informal recycling? The study was unable to address the challenges associated with informal recycling. This study only identified indicators that may be helpful. Findings effective approaches that can help to tackle the challenge of WEEE management may be useful.

\section{Research Gap}

Several efforts have been made by researchers in the past to proffer a solution to the challenges associated with informal recycling, but the challenge still remains. No one has been able to reduce the challenges. This is largely due to the difficulties associated with getting the informal recyclers to adopt WEEE best management practices, since they are mostly illiterate. This makes the challenges associated with informal recycling an unending problem, especially in Nigeria and other developing countries faced with the same challenge. This research gap in this field forms the basis of this study.

\subsection{The Need to Reduce the Activities of Informal Recyclers in WEEE Management in the Study Location}

Informal recycling appears to be the key reason for the challenges associated with WEEE management [52]. Hence, a drastic reduction in the activities of informal recyclers will help to revolutionise the WEEE management practice in Nigeria and other developing countries that use similar recycling methods. The services of the informal recyclers are faced with the following challenges, according to [53]:

a. They lack training, orientation, and formal education on the use of personal protective equipment, PPE, and first aid treatment application during an emergency;

b. They lack the basic facilities required for effective WEEE management;

c. The government does not offer them financial support and any form of recognition;

d. Their WEEE management techniques expose them, individuals in the location, and the environment to risk; 
e. They usually do not adopt the use of safety gadgets to protect themselves from materials that are hazardous or expose them to health risk;

f. There is no access to training opportunities on the types of materials and waste, technologies, finance, and conditions of the environment;

g. There is no access to required health facilities;

h. They lack the appropriate facility and knowledge to manage substances/elements that are harmful to life and the environment.

\subsection{How to Reduce the Activities of Informal Recyclers in WEEE Management}

Ceballos et al. [28] opined that observing the following tips can help to reduce the menace associated with WEEE management:

- Avoid purchasing electrical or electronic devices that you do not need;

- Patronise the manufacturers of electronic or electrical devices that adopt the use of green technologies, as well as take-back systems;

- Encourage WEEE recyclers in your community. You can throw away your WEEE by visiting their location;

- Avoid discarding electrical or electronic devices, such as solar panels, light bulbs, batteries, and printed circuit boards, into regular refuse.

This study attempts to reduce the activities of informal recyclers in the business of WEEE management through the design of a new management system that will still provide the informal recyclers with an opportunity to earn money. The WEEE management system allows for informal recyclers to earn money from WEEE gathering or collection, whereas the other activities, such as treatment, recycling, etc., are handled by government-trained experts. Furthermore, just-in-time (JIT) lean management principles are also adopted to enhance the efficiency of the method.

\subsection{WEEE Management System}

This study intends to reduce the activities of informal recyclers in the MTN phone village, Rumukurushi in Port Harcourt, Nigeria. This will be achieved via the combination of two different approaches, namely:

- Recovering WEEE from residents, informal recyclers, and the remaining part of the public for sorting, processing, treatment, and recycling by government-approved agencies;

- $\quad$ Applying the just-in-time (JIT) lean management principles to the current WEEE management system in the location.

The WEEE management model is shown in Figure 2.

The WEEE management system ensures that only government-approved agencies are allowed to manage WEEE. WEEE is collected from residents, informal recyclers, and the remaining part of the public, and this will help to cut down informal recycling and the challenges associated with it. The application of the just-in-time concept is applied by government-approved agencies after WEEE collection/gathering. Furthermore, the dismantling of WEEE is carried out by experienced and trained government personnel to ensure that the dismantled WEEE materials follow appropriate processing, such as re-use, further treatment, refining, etc., as shown in Figure 2.

\subsubsection{Lean Concepts}

The word "lean" implies a set of solutions or activities to remove waste, cut down "non-value-added (NVA) operations" and increase "the value-added" ones [54,55]. Lean safety refers to a technique fashioned for the identification of and reduction in waste in some processes, and, hence, reduces accidents and illnesses in the workplace [56]. A research effort made by Hamja et al. [57], explains that the key objective of the lean approach is waste elimination, as it helps to eliminate "waste of non-value process during production". The same report shows that safety and success can be enhanced through the applications 
of lean tools, such as lean principles, just in time (JIT), 5S, etc. The lean approach makes it possible for the adoption of a $5 \mathrm{~S}$ methodology that involves the application of five steps; these are sort, straighten, shine, standardise, and sustain, as in [55,57]. Recent research work by Alkhoraif et al. [58] concluded that the lean concept refers to a more efficient utilisation of available resources when it matters the most, as material and time waste are pinpointed and eliminated, creating room for maintenance of quality with diminishing cost.

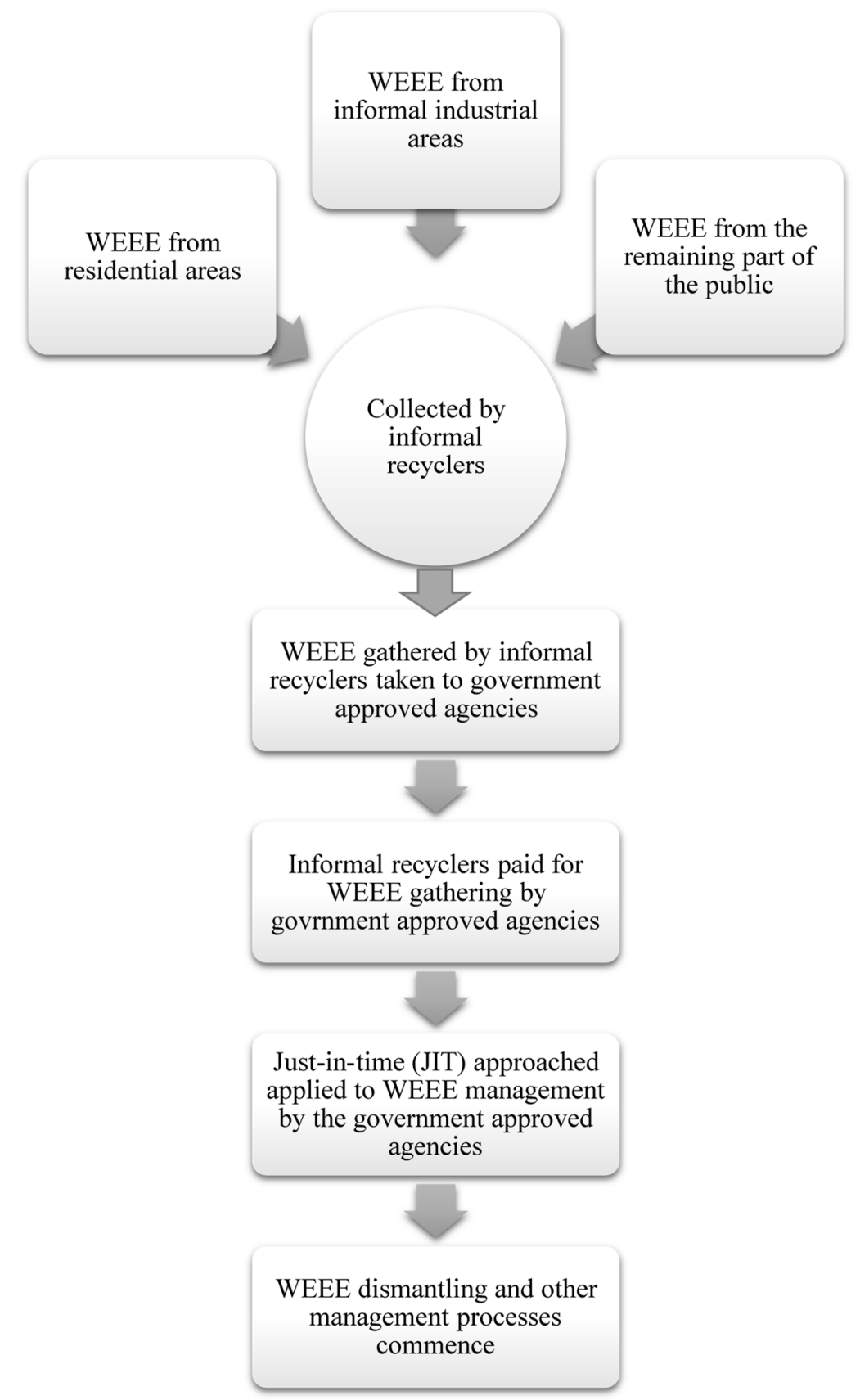

Figure 2. WEEE management model.

\subsubsection{Just-in-Time Concept}

This study adopts the just-in-time concept in the management of WEEE. The justin-time concept, as investigated by McKinney and Scalia [59], increases efficiency while waste is reduced by collecting goods or items only as they are demanded in the process of production. The concept decreases wastage and enhances the productivity, efficiency, 
and flow of the production process [60]. In Wu et al. [61], the just-in-time management concept can help to reduce "the waiting times of workers and equipment". Just-in-time comprises three key objectives, and these are reduction or elimination of every form of inventory, the unmasking of the inefficiencies that exist in the production process, and the application of current production techniques to reduce inefficiencies identified in the process [62]. Just-in-time entails producing only that which is required and at the time it is required, as well as the amount needed at a specific time [63]. The just-in-time concept is applied to WEEE management in the following ways: the collection of WEEE from the residents, informal recyclers, and the remaining part of the public will only be carried out on-demand. This implies that the further collection of WEEE is carried out when those already collected have been processed and there is room to accommodate new ones. The benefits of this concept are as follows:

a. WEEE collection and gathering at government-approved collection centres will be carried out on demand;

b. WEEE gathered are processed, and the dumping ground at the government-approved collection centres are emptied for re-use;

c. The health challenges associated with offensive odour from the decay of WEEE are eliminated, since the WEEE collected are processed almost immediately;

d. It helps to reduce waste of land or storage space, unlike the existing WEEE management system, in which WEEE occupies a lot of space and produces an offensive odour that can cause health challenges;

e. The collection and gathering of WEEE serves as a source of income to the informal recyclers and all those involved in WEEE collection.

1.4.3. Advantages of the WEEE Management System for Port Harcourt City, Nigeria

The benefits of the WEEE management system include:

- It will enhance the safe and sustainable disposal of hazardous materials;

- Valuable materials or precious metals, such as gold, copper, etc., will be recovered for reuse and recycling;

- It will enhance the sorting of hazardous materials from non-hazardous materials after dismantling;

- It will help to check and reduce the activities of informal WEEE recyclers, since they lack the required skills and experience for proper WEEE treatment, processing, and disposal;

- With this system in place, the recovery, reduction, reuse, repurpose, and recycling of WEEE is possible;

- It will create job opportunities;

- It will help to make suggestions to policymakers on how to address the issues related to WEEE;

- It will help to reduce other risks associated with informal WEEE processing, treatment, and disposal in Nigeria.

It will also help to create awareness of the need for WEEE to be handled by properly trained and experienced personnel.

\section{Materials and Method}

The study methodology comprises the research philosophy, research approach, data collection method, and data analysis method. The interpretivist research philosophy was adopted in this study. In Kivunja and Kuyini [64] (p. 33), with interpretivist research philosophy, the theory does not come before research, but comes after it. This implies that "it is grounded on the data generated by the research act". In order to take a look at informal recycling in the city of Port Harcourt, Nigeria, a small location, known as MTN phone village, Rumukurushi, was used as a case study. Hence, a qualitative research approach was adopted for the study. In a study carried out by Ragab and Arisha [65] (p. 3), a new theory development can be achieved with the help of two approaches: it is either 
carried out with the use of "deductive reasoning" or through "inductive theory building". According to the same research work, the deductive approach allows for quantitative data collection, whereas the inductive approach allows for qualitative data collection. This study adopted the inductive approach, since it requires qualitative data.

Data gathering for the study was achieved with the help of semi-structured phone interviews. The semi-structured interview method was adopted to enable flexibility in the nature and amount of questions asked $[65,66]$. The study preferred a face-to-face interview, but it was not achievable due to the prevailing COVID-19 pandemic. The thematic analysis technique was adopted for the analysis of the data.

\section{Data Collection Using Semi-Structured Phone Interviews}

Due to the prevailing COVID-19 pandemic during the period of data collection, a face-to-face interview was not possible, as it requires traveling by flight from the UK to Port Harcourt, Nigeria; hence a semi-structured phone interview was carried out instead. The respondents are members of staff of a WEEE regulatory agency in Port Harcourt, Nigeria. According to a study carried out by Ragab and Arisha [65] (p. 12), two main kinds of interviews exist, namely, structured and unstructured. An interview that adopts the structured approach may achieve a few ranges of answers, and this is because the entire participants are provided with a "set of identical questions which are asked in a predetermined order". It takes the form of a questionnaire. The unstructured interview does not adopt the use of "a set of identical questions", i.e., they are not standardised. Furthermore, in between these two (2) kinds of interviews is the semi-structured interview, which adopts the use of "a set of predetermined questions" and also creates room for a reasonable amount of flexibility; for example, new questions can be asked, existing ones can be thrown away, and there is also room for new ideas to emerge from the conversation.

The respondents are residents of the city of Port Harcourt, Rivers State, Nigeria. Each of the participants were interviewed for twenty minutes, with the conversations recorded with an audio recorder. The group of individuals interviewed is within the age range of 20-45 years of age. A total of twenty-five participants were interviewed, and their basic details are shown in Table 1.

\section{Empirical Findings}

The organisation selected for this study is one charged with the responsibility to regulate WEEE management in the city of Port Harcourt, Nigeria. The Port Harcourt branch of the organisation is responsible for enforcement of compliance with policies, standards, legislation, and guidelines for water quality, environmental health, and sanitation, including pollution abatement. Furthermore, the numerous tasks carried out by the organisation also include the enforcement of compliance with regulations on the importation, exportation, production, distribution, storage, sale, use, handling, and disposal of hazardous chemicals and waste, other than in the oil and gas sector.

\section{Data Analysis Method}

An edited transcription of the semi-structured phone interview was carried out and a thematic analysis was also carried out to enable the separation and the performance of a critical discussion on the findings of the study. The thematic analysis also makes it possible to assess and pinpoint relevant discoveries and patterns. In Caulfield [67], thematic analysis is defined as a technique that is utilised to analyse qualitative data or information used when dealing with text; for example, interview transcripts. The thematic method of data analysis makes it possible for the user to assess the data carefully and to pinpoint themes that are common, such as patterns and topics, as well as ideas that appear frequently. 
Table 1. Interviewee basic details.

\begin{tabular}{ccc}
\hline Position of Participants & Number of Interviewees & Duration of the Interview (Minutes) \\
\hline Senior Manager (SM), dismantling & 4 & 20 \\
\hline Senior Manager (SM), treatment and packaging & 4 & 20 \\
\hline Senior Manager (SM), human resources & 1 & 20 \\
\hline Storage officer & 4 & 20 \\
\hline Officer I & 4 & 20 \\
\hline Officer II & 4 & 20 \\
\hline WEEE collector & 4 & 20 \\
\hline
\end{tabular}

A study carried out by Caulfield [67] and Nowell et al. [68] opined that thematic analysis can be executed in a number of approaches, but the most common is carried out with the help of six steps, as stated below:

i. Becoming familiar with the available data;

ii. Initial code generation;

iii. Themes generation;

iv. Reviewing of themes;

v. Definition of themes, as well as naming;

vi. Report writing up.

According to a study carried out by Nowell et al. [68], thematic analysis is an approach utilised to organise, describe, analyse, and report themes that are present in a data set. Two major approaches are used when executing thematic analysis: they are the deductive approach, which requires many preconceived themes to be introduced into the data, and the inductive approach, which requires the data to be allowed to determine the theme [67]. In Elliott [69] (p. 2851), code generation is the second stage of the thematic analysis technique, and this is because, "Text data are dense data, and it takes a long time to go through them and make sense of them".

The term code generation implies that some parts of the text that are usually phrases or sentences are highlighted; then, shorthands, referred to as codes, are created in order to describe the content. Each of the phrases take a unique colour to differentiate them from others. Each of the codes stands for an idea or message conveyed in that particular section of the text, and, as one continues to go over the text, the introduction of new codes is possible. Eventually, the entire data are gathered together in groups that are defined by code. The codes make it possible for one to achieve a more concise overview of the key points and ideas that appear repeatedly in the data $[67,70,71]$.

Nowell et al. [68] posits that themes are important concepts that join together considerable pieces of the data at the moment they are identified. They are either deductively generated from earlier research, theory, etc., or inductively generated from the available raw data.

This study adopted the inductive approach of thematic analysis, and the results are given below.

\section{Ethical Issues}

Each of the participants were handed a written informed consent. It was clearly stated in the study brief that they are free to withdraw at any time, should they desire to do so. Each of the participants gave consent to the recording of the interview, while the contents were anonymised and transcribed. Each of the interviews carried out were stored on an encrypted computer. There were no issues of ethical concerns from the start to the end of the process. 
Interview Procedure

Each of the participants were contacted via email and sent a copy of the outline on the purpose and requirements of the study. To ensure confidentiality, each of the participants were offered an explanation that their identity-for example, their names-will be removed from the transcribed data, and also that the idea will not be attributed to any of them in any way. The moment that informed consent from the participants was achieved, each of them were also reminded of their right to put an end to the interview at any time. The interviews were conducted with each of the participants. A semi-structured phone interview was carried out in this study, instead of the face-to-face method, as a result of the prevailing COVID-19 pandemic. A semi-structured interview was adopted for the study. This is because a semi-structured interview utilises "a set of predetermined questions" and also creates an allowance for a significant amount of flexibility. Hence, new questions can be asked, and "existing ones" can be removed, and there is room for the introduction of new ideas or concepts [65] (p. 8). The procedure of the phone interview was carried out like that in [72], where it was made conducive for each participant to emphasise on issues that they consider more relevant instead of depending on what the researcher deemed relevant.

\section{Coding and Theme Generation}

The data analysis process started with familiarisation, which entails listening to the audio recording of each of the participants. This was followed by an intelligent verbatim method of audio transcription in order to help with the elimination of irrelevant fillers, such as "hmm", "yeah", "you know", etc. The coding of the data followed. Codes such as A, B, C, etc., were initially assigned to the participants, as shown in Table 2.

Table 2. Codes assigned to participants.

\begin{tabular}{cc}
\hline Position of Participants & Code \\
\hline Senior Manager (SM), dismantling & $\mathrm{A}$ \\
Senior Manager (SM), treatment and packaging & $\mathrm{B}$ \\
Senior Manager (SM), human resources & $\mathrm{C}$ \\
Storage officer & $\mathrm{D}$ \\
Officer I & $\mathrm{E}$ \\
Officer II & $\mathrm{F}$ \\
WEEE collector & $\mathrm{G}$ \\
\hline
\end{tabular}

New codes were later generated in order to help with the capturing of key points that are relevant to the study. Furthermore, the collation of the quotations that relate to each of the themes made it possible for the relevant patterns to emerge.

\section{Results}

A total number of thirty-four quotations was generated from the transcribed semistructured phone interview, out of which, ten first-order themes were generated, and these are:

i. Manual dismantling practices adopted by the informal recyclers, and what good practice should be;

ii. The treatment of cables by informal recyclers to recover copper and the associated risks;

iii. The dismantling of printed wiring boards by informal recyclers and the processes involved;

iv. The willingness of informal recyclers to obey government guidelines during WEEE handling, dismantling, treatment, burning, etc.;

v. The enhancement of the activities of informal recyclers via training;

vi. The willingness of informal recyclers to get paid for WEEE collection while they quit other WEEE management activities, such as treatment, burning, etc.; 
vii. Lean implementation effectiveness in WEEE management and its impact on the reduction in both waste and the non-value-adding process;

viii. Lean implementation effectiveness in WEEE management and its effects on storage space in the site;

ix. Application of the just-in-time (JIT) concept in WEEE management and how it relates to waste reduction;

x. The application of the JIT concept in WEEE management and how it relates to the reduction in storage and waiting time.

a. Manual dismantling practices adopted by the informal recyclers and what good practice should be.

This theme refers to the way informal recyclers carry out their manual dismantling activities. Several opinions regarding both bad and good manual dismantling practices were raised. The first issue raised is on what appears to be a bad or good practice in the technique adopted by informal recyclers during the manual dismantling of refrigerators. It appears that the manual dismantling carried out by the informal recyclers is not safe, and needs to be replaced by good practice. Some of their responses were:

"The last time I visited one of the recycling sites, the informal recyclers engage in forced opening of the refrigerators, they either smash and/or break the plastic or metal encasing structure, that practice is bad ... ", B1, 22.07.2020.

Some of the participants claimed that, during their visits to the locations, they observed that the informal recycler is less concerned about the use of PPE.

"I did not see them make use of safer devices like a screwdriver to help with controlled opening, they even crush the inside part without any form of personal protective equipment, PPE ..." A1, 20.07, 2020.

"What I observed during one of my visits to one of the locations is that they don't make use of PPE, instead to just smash and break the refrigerator, without the proper separation and containment of hazardous constituents being released and this practice is bad ..." C1, 23.07.2020.

According to some of the participants, the informal recycler exposes themselves, as well as the environment, to health risks, and some try to explain what a good refrigerator manual dismantling should look like.

"As regards the dismantling of refrigerators, I think the informal recyclers need complete orientation and training on the dangers of their technique, as they are exposing themselves as well as the environment to health risk... " B2, 22.07.2020.

"The manual dismantling done by the informal recyclers is bad, a good practice begins with used refrigerator being returned by the public to authorised collection centres and facilities and none is existing, then they should be stored in a proper centre, before any treatment, fridges should be separated based on the type of refrigerants gases they contain ..." B3, 22.07.2020.

"I think the informal recyclers should only be allowed to collect WEEE as their style of dismantling refrigerators is not safe, a good practice includes the use of tools fit-forpurpose, PPE, and training to increase their knowledge on WEEE management and the dangers associated with unsafe practice ... " B4, 22.07.2020.

b. The treatment of cables by informal recyclers to recover copper and the associated risk.

This theme refers to how copper is recovered from cables by informal recyclers and the associated risk. To some of the participants, the informal recyclers set the cables on fire and extract the copper, regardless of any associated health risk.

"On three different occasions, I observed the informal recycler burn off waste cables in open fires that incinerate the outer insulating plastic covering leaving copper as a 
residue, which is then collected without considering the associated health risk... " $A 2$, 20.07.2020.

"The informal recycler is not concerned about any associated health risk, they just burn the waste cable to extract the copper ... " D1, 17.07.2020.

One of them condemned the burning of the insulation part of cables, as it releases harmful compounds to the environment.

"Burning of the insulation part of cables, dioxins and mercury, as well as harmful chlorine, compounds e.g., polychlorinated biphenyls are released, these make the practice bad..." $A 3,20.07 .2020$.

Furthermore, from some of the participants, there are better ways to recover copper from the cable, as burning is an unsafe practice.

"Stripping and mechanical granulation of cables is a good technique, it is simple, its cost is relatively low, and the insulation part of the cable can be recovered safely instead of burning ..." D2, 17.07.2020.

"Instead of using the burning technique, I think the use of chemical treatment is good, besides, heat recovery is another option where the cables can be incinerated in hightemperature kilns with proper emission control, while the heat is captured for use ..." E1, 15.07.2020.

c. Dismantling of printed wiring boards by informal recyclers and the processes involved.

This theme sheds light on the dismantling of printed wiring boards (PWB) by informal recyclers, and the bad and good practices adopted in the process. To some of the participants, the techniques adopted to recover some elements from the printed wiring board tend to be hazardous.

"During my last visit to one of the shops own by an informal recycler, I noticed they adopt the wet chemical leaching technique to extract metals such as gold or silver, the technique is hazardous and should be carried out only by experienced professionals in the laboratory ... "F1, 16.07.2020.

"Some of the informal recyclers tend to apply heat to solder in order to de-solder certain components on PWB, they usually carry out this activity under uncontrolled conditions given room for the release of hazardous substances ... " F2, 16.07.2020.

Others suggested that it should be carried out in a manner that guarantees the safety of lives and properties and not through any of the primitive techniques adopted.

"I think the parts of the printed wiring boards should be removed by unscrewing and dislodging, goggles and gloves should be worn besides, it is better to store different fractions in their respective containers ... " E3, 15.07.2020.

"It is advisable to work on one material at a time, e.g. first remove all aluminium parts and store them in the aluminium container, next, remove all the ferrous parts and store them in the relevant container and so on, this will help to avoid mixing up materials... " G1, 14.07.2020.

d. The willingness of informal recyclers to obey government guidelines during WEEE handling, dismantling, treatment, burning, etc.

This theme was fashioned to assess the general opinion of the members of staff of the WEEE regulatory organisation on the willingness of the informal recyclers to obey government guidelines during the discharge of their duties. According to most of the participants, no less than $85 \%$ of the informal recyclers are illiterates and, hence, it is difficult for them to gain awareness or knowledge on the need to follow government guidelines in the discharge of their duties. 
"Majority of the informal recyclers do not have basic education as they cannot read or write in English language, some have English speaking deficiency, this makes learning and development extremely difficult ... " C1, 23.07.2020.

"The few among them who have good English speaking and listening skills are willing to obey government's guidelines on WEEE management ... " A1, 20.07.2020.

Some of the participants are of the opinion that the government should either stop or discourage the activities of informal recyclers.

"Yes, obeying government's guidelines on the discharge of their duties is good but this may be difficult to realise as they are mainly illiterates ..., maybe informal recycling should be discouraged ... " G1, 14.07.2020.

"There is a lot to be done to make the informal recyclers obey government guidelines due to their level of education, I feel that government should either put an end to the activities of informal recyclers or limit their services to WEEE collection only ... " A3, 20.07.2020.

e. The enhancement of the activities of informal recyclers via training

This theme focuses on the response of the participants and on their opinion regarding the training needs of the informal recyclers. The majority of the participants support the need for training for the informal recyclers, but emphasised that illiteracy is the main challenge facing the informal recyclers, as this hinders development.

"Organising regular training workshops for the informal recyclers will enhance their skill acquisition but there is a high level of illiteracy among them ... " G3, 14.07.2020.

"Illiteracy is the main challenge I observed with the informal recyclers the last time I visited their site to distribute fliers, some of them tend to hide for fear of being apprehended due to the illegal nature of their business" F4, 16.07.2020.

f. The willingness of the informal recyclers to get paid for WEEE collection while they quit other WEEE management activities, such as treatment, burning, etc.

This theme embraces responses from the participants regarding offering payment to informal recyclers for WEEE collection, while an effort is made to stop them from participating in other WEEE management activities. To some of the participants, it will be a welcome development if that can be implemented, as the target of the informal recyclers is to earn money; with that approach in place, informal recyclers will concentrate more on WEEE collection to raise cash for themselves. To others, it helps to gradually discourage them from the other WEEE management activities, such as dismantling, treatment, burning, etc.

"We have had several conversations with the informal recyclers, they engage in the recycling business to enable them to earn a living and will be happy if they can get money from the government or the private individuals for WEEE collection ... " C1, 23.07.2020.

"They actually find it easy to gather WEEE, as such if the government can prepare to pay them for WEEE collection and in the process stop them from other activities like dismantling, treatment, etc., it will be a step in the right direction ... " E4, 15.07.2020.

"... money is the target in the business, the moment they start getting paid for WEEE collection, they will concentrate more on that aspect and gradually their concentration on the other WEEE management activities will depreciate ... " F4, 16.07.2020.

g. Lean implementation effectiveness in WEEE management and its impact on the reduction in both waste and the non-value-adding process.

This theme focuses on the lean concept, its implementation, and its effectiveness. An effort was made to offer some explanations to the participants on the meaning of the term lean. In Deranek et al. [54], lean implies the development of a value stream that 
enables the elimination of all waste, including time, and facilitates a level schedule. In this context, waste is referred to as any activity that does not add value but becomes integral to production. To the majority of the participants, the concept is new, and to some of them who claim they have heard about the concept before, they seem to not understand the application of the concept to waste management.

"... Since, the concept has to do with the elimination of waste, that's fine, I am sure, this will help to cut down the amount of WEEE in circulation ... " A4, 20.07.2020.

"I read online about this concept recently but yet to understand its application but I think it is beginning to make sense to me now ..." D2, 17.07.2020.

"One of the challenges we experience at WEEE dumpsites is that it occupies space that normally would have been put to good use ... " D3, 17.07.2020.

h. Lean implementation effectiveness in WEEE management and its effects on storage space in the site.

This theme focuses on the relationship between effective lean implementation on WEEE management and storage space in the site. Most of the participants attempted to think outside the box, and came up with ideas on how the application of lean can facilitate the reduction in storage space.

"... from all I have gathered from you, with this concept, WEEE collection can be carried out on demand, it therefore means, any available space for storage can be put to good use ..." D1, 17.07.2020.

"If more WEEE can be collected when there is a need, it means more will be collected if the available ones are processed and there is space for new intakes, this will go a long way to reduce the amount of space used for storage ... " D2, 17.07.2020.

i. Application of the just-in-time (JIT) concept in WEEE management and how it relates to waste reduction

This theme entails the application of the just-in-time concept and how it results in waste reduction. The participants feel that, with the timely processing of WEEE materials, there will certainly be a reduction in waste

“WEEE collection, dismantling, etc. carried out in a timely manner, implies a timely waste reduction ..." B3, 22.07.2020.

"If collected WEEE materials are processed in a timely manner, it will lead to waste reduction ... "F2, 16.07.2020.

j. The application of the JIT concept in WEEE management and how it relates to the reduction in storage and waiting time

This theme embraces the participants' opinion on the application of the JIT concept in WEEE management and its impact on the reduction in storage and waiting time. The majority of the participants believe it facilitates the reduction in storage and waiting times.

"Since, this concept involves the on-time supply of WEEE for example, at the collection point when in demand, the waiting time of the workers as well as the duration at which they are kept or stored before demanded, also reduces ... " A1, 20.07.2020.

"With timely response to WEEE management activities, idleness at the site is drastically reduced and consequently waiting time also reduces ... " B2, 22.07.2020.

Furthermore, three second-order themes were generated from the ten first-order themes in order to facilitate effective WEEE management. The three second-order themes are:

i. Safety enhancement during the performance of WEEE management activities;

ii. Partnership for effective WEEE management;

iii. Strategies to enhance effective WEEE management. 
The diagram of the effective WEEE management and the associated themes are shown in Figure 3.

- Manual dismantling practices adopted by the informal recyclers and what good practice should be

- The treatment of cables by informal recyclers to recover copper and the associated risks

- Dismantling of printed wiring boards by informal recyclers and the processes involved.

1

Safety enhancement during the performance of WEEE management activities

- The willingness of informal recyclers to obey government guidelines during WEEE handling, dismantling, treatment, burning, etc.

- The enhancement of the activities of informal recyclers via training

- The willingness of the informal recyclers to get paid for WEEE collection while they quit other WEEE management activities such as treatment, burning, etc.

- Lean implementation effectiveness in WEEE management and Its impact on the reduction of waste and non-value-adding process.

- Lean implementation effectiveness in WEEE management and its effects on storage space in the site.

- Application of Just-in-time (JIT) concept in WEEE management and how it relates to waste reduction

- The application JIT concept in WEEE management and how it relates to a reduction in storage and waiting time

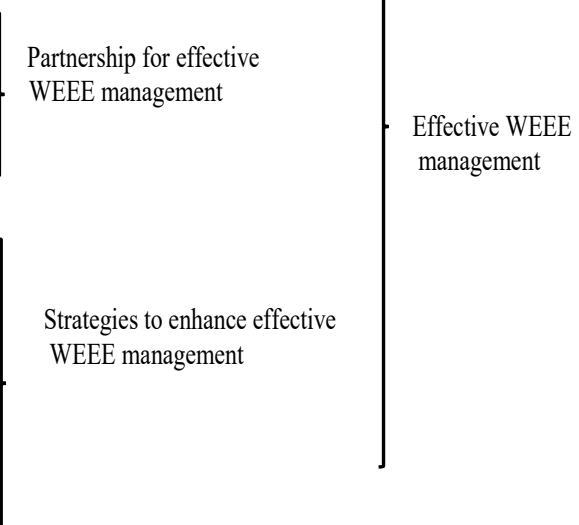

Figure 3. Effective WEEE management and associated themes.

\section{Discussion}

The focus of this study is to assess the activities of the informal recyclers, the knowledge of the WEEE regulatory body on the activities of the recyclers in MTN phone village in the city of Port Harcourt, Nigeria, and their knowledge on the just-in-time concept as an applicable lean approach. The interview was conducted to help with the understanding of the exact situation, and, besides, it is of importance to ascertain if there are any themes or patterns that are common in the experiences of the participants, as emphasised in a study by [71]. The findings show that the manual dismantling of WEEE carried out by the informal recyclers in the study location is not safe. It is carried out without the use of personal protective equipment. Conversely, because of the unsafe dismantling procedures adopted, they tend to expose themselves, as well as the environment, to health-related risks. For an effective and safe manual dismantling system to be in place, there is a need to adopt the best practices in the management of WEEE [73].

In Baldé et al. [74], dismantling activities performed without adequate facilities, means, and skilled individuals usually create room for additional hazards to people and the environment. The adoption of the best practices in manual dismantling is highly encouraged, as a lot of work-related injuries are associated with it [75]. WEEE material that requires dismantling must first be made non-hazardous. This implies the removal of every hazardous component, and, for laptops and computers, data destruction has to be carried out with the help of designated equipment before dismantling [73].

Many of the participants are ignorant of the risk associated with the improper burning of WEEE. Among the participants are also those who emphasised that there are better ways to recover copper from cables, and that burning is unsafe. In Lenz et al. [76], the burning of the insulating part of waste cables using an open fire to extract copper was found to be the worst technique to adopt. The burning of cables in the open air to extract copper has a serious effect on the informal recyclers' health, as it produces both hydrochloric acid and many other materials, which give rise to acute respiratory challenges [77].

It was also gathered from the interview that it is not going to be easy to train the informal recyclers on the best practices or to make them go into partnership with the government on WEEE management, as they are mostly illiterate. Some of the participants are of the opinion that the government should either stop the activities of informal recyclers 
or discourage them. This is because their level of illiteracy hinders WEEE management knowledge acquisition and government partnership. Furthermore, it was made clear from the interview conversation that the main target of the informal recycler is to raise money for themselves. Any effort made by the government or private individuals to pay them money for WEEE collection is a step in the right direction. This is because it has the potential to make them concentrate more on WEEE collection, while they gradually become discouraged from the other activities that form part of WEEE management, such as treatment, recycling, burning, etc.

At the beginning of the conversation, with most of the participants, the application of the just-in-time concept, an aspect of lean principles, appears to be new, but as the conversation continues, several of them tried to think outside the box and came up with their opinion on the subject. To some of them, the application of the lean concept facilitates the reduction in storage space. It was evident from the findings that the timely processing of WEEE materials using the JIT approach will result in a reduction in waste, storage, and waiting times. In Manzouri et al. [78], the lean concept has the potential to reduce the waste and cost. From the interview conversion, idleness among the WEEE workers is one of the issues that the just-in-time approach stands to cater for.

In Cerra [79], less space is required with the application of the just-in-time concept, as there is a quicker processing of the collected WEEE; hence, a place of storage or warehouse is not required. In addition, the faster processing of WEEE gathered prevents the storage of already collected WEEE, hence reducing waste. In Wu et al. [61], safety hazards that are hidden, as well as idleness on the part of workers and devices, are eliminated.

One of the managers (B1) observed that the informal recyclers' approach to the dismantling of refrigerators is bad, as they either smash and/or break the plastic or metalencasing structure. Another of the managers (A1) observed that informal recyclers do not adopt any form of controlled opening while attempting to dismantle the refrigerator, as they even crush the inside part without any form of PPE. Judging by the experience of a different manager (C1), it was suggested that informal recyclers disregard the use of PPE and the risk associated with their style of dismantling. It is obvious that informal recyclers will continue to expose themselves, others, and the environment to risks if their activities are not checked. Managers A2 and A3 spoke against the burning of the insulation part of cables, dioxins, mercury, chlorine, etc. This is because poisonous substances are being released into the environment.

Manager $\mathrm{C} 1$ observed a high level of illiteracy among the informal recyclers. This makes it almost impossible for training to be administered to them on the best WEEE management practices. Manager A3 recommended that the government should stop the informal recyclers from engaging in WEEE management, as much has to be carried out in order to get them to the point where they can adopt the WEEE management best practices. This is largely due to their high level of illiteracy. Manager C1 observed that informal recyclers will be happy if they can be paid by the government or private individuals for WEEE collection while they quit the other WEEE management practices. Limiting the activities of informal recyclers to WEEE collection only will go a long way to reduce the challenges associated with informal recycling.

Manager B3 identifies timely waste reduction as one of the advantages of the application of the JIT concept. Manager A1 identifies a reduction in the waiting time of workers and WEEE storage space as one of the advantages of the application of the JIT concept. Finally, Manager B2 opined that the idleness on-site and waiting time is drastically reduced with the application of the JIT concept. Their observations imply that there are benefits that are achieved with the application of the JIT concept.

\section{Conclusions}

The research work reviewed past works of literature on WEEE management in an attempt to reduce the activities of informal recycling in the city of Port Harcourt, Nigeria. A new WEEE management concept for Port Harcourt is being developed that ensures 
the collection of WEEE from residents, informal recyclers, and the remaining part of the public, coupled with the application of the just-in-time (JIT) management concept. In this study, the informal recycler is not involved with WEEE treatment, dismantling, refining, and disposal, but still gains revenue from the process. The study shows that providing a financial inducement to the informal recyclers by paying them for WEEE gathering has the potential to make them partner with government agencies for a collective and effective management system. Furthermore, reducing the level of participation of informal recyclers in the aspect of WEEE management that requires experienced hands implies a reduction in the challenges associated with their involvement. WEEE management is now the sole responsibility of the government-approved offices and trained personnel, and this offers safety, efficiency, and an increased productivity. The outcome of this study will help to reduce the activities of informal recyclers in the MTN phone village, Rumukurushi, Port Harcourt, Nigeria, and other cities and nations faced with similar challenges. With this development, informal recyclers will be allowed to collect WEEE only, as they will not be allowed to perform other WEEE recycling activities. A reduction in the waiting time of workers and WEEE storage space is achieved. This offers safety, efficiency, and an increased productivity. This will help to revolutionise the WEEE management system in the city of Port Harcourt, Nigeria, and any other location that adopts the system.

Author Contributions: Conceptualisation: O.O., A.H. and E.V.; methodology: O.O., A.H., E.V. and L.I.; formal analysis: O.O., A.H., E.V. and L.I.; investigation: O.O.; resources: O.O., A.H. and E.V.; data curation: O.O., A.H., E.V. and L.I.; writing-original draft preparation: O.O.; writing-review and editing: O.O., A.H., E.V. and L.I.; visualisation; O.O., A.H. and E.V.; supervision: A.H. and E.V.; project administration: A.H. and E.V.; funding acquisition, O.O. All authors have read and agreed to the published version of the manuscript.

Funding: This research received no external funding.

Institutional Review Board Statement: The study was conducted according to the guidelines of the Declaration of Helsinki, and approved by the Ethics Committee of the School of Computing, Engineering \& Physical Sciences, University of the West of Scotland (reference number 21-8607-3338).

Informed Consent Statement: Informed consent was obtained from all subjects involved in the study.

Data Availability Statement: Not applicable.

Conflicts of Interest: The authors declare no conflict of interest.

Sample Availability: Samples of the compounds are not available.

\section{References}

1. Konya, R.S.; Babatunde, B.B.; Iniefe, D. Assessment of e-waste status in Port Harcourt city and its environs. Environ. Sci. 2015, 3, 45-66. [CrossRef]

2. Amadi, A.I.; Chijioke, A.K. Economic and Environmental Sustainability of Informal Sector Recycling of Construction and Demolition Waste in Nigeria. AASCIT J. Environ. 2018, 3, 1-10.

3. Ohajinwa, C.M.; van Bodegom, P.M.; Vijver, M.G.; Peijnenburg, W.J.G.M. Health risks awareness of electronic waste workers in the informal sector in Nigeria. Int. J. Environ. Res. Public Health 2017, 14, 911. [CrossRef]

4. Omosimua, I.J.; Oluranti, O.I.; Obindah, G.; Busayo, A. Working Conditions and Career Aspirations of Waste Pickers in Lagos State. Recycling 2020, 6, 1. [CrossRef]

5. Amechi, E.P.; Oni, B.A. Import of Electronic Waste into Nigeria: The Imperative of a Regulatory Policy Shift. Chin. J. Environ. Law 2019, 3, 141-166. [CrossRef]

6. Wideman, B.N. Grappling with the African E-Waste Pandemic: Contributing Factors and Future Deterrence. Master's Dissertation, Portland State University, Portland, OR, USA, 2019.

7. Bilitewski, B.; Wagner, J.; Reichenbach, J. Best Practice Municipal Waste Management Information Pool on Approaches towards a Sustainable Design of Municipal Waste Management and Supporting Technologies and Equipment; Umweltbundesamt: Dessau-Roßlau, Germany, 2018.

8. Erhardt, A.J.; Rezende, C.E.; Walker, B.G.; Franceschi, D.; Downie, D. Mercury concentrations and awareness in Campos dos Goytacazes, Brazil: Baseline measures for examining the efficacy of the Minamata Convention. J. Environ. Stud. Sci. 2015, 5, 517-525. [CrossRef] 
9. Aidonis, D.; Achillas, C.; Folinas, D.; Keramydas, C.; Tsolakis, N. Decision Support Model for Evaluating Alternative Waste Electrical and Electronic Equipment Management Schemes-A Case Study. Sustainability 2019, 11, 3364. [CrossRef]

10. Rai, V.; Liu, D.; Xia, D.; Jayaraman, Y.; Gabriel, J.-C.P. Electrochemical Approaches for the Recovery of Metals from Electronic Waste: A Critical Review. Recycling 2021, 6, 53. [CrossRef]

11. Grigorescu, R.M.; Grigore, M.E.; Iancu, L.; Ghioca, P.; Ion, R.-M. Waste Electrical and Electronic Equipment: A Review on the Identification Methods for Polymeric Materials. Recycling 2019, 4, 32. [CrossRef]

12. Herat, S. 3R Technologies for WEEE. In Proceedings of the 8th Regional 3R Forum in Asia and the Pacific, Indore, Madhya Pradesh, India, 9-12 April 2018; pp. 1-47.

13. Kumar, S.; Smith, S.R.; Fowler, G.; Velis, C.; Jyoti, K.S.; Arya, S.; Kumar, R. Challenges and opportunities associated with waste management in India. R. Soc. Open Sci. 2017, 4, 1-11. [CrossRef]

14. Akon-Yamga, G.; Daniels, C.U.; Quaye, W.; Ting, B.M.; Asante, A.A. Transformative innovation policy approach to e-waste management in Ghana: Perspectives of actors on transformative changes. Sci. Public Policy 2021, 48, 387-397. [CrossRef]

15. Cui, J.; Zhang, L. Metallurgical recovery of metals from electronic waste: A review. J. Hazard. Mater. 2008, 158, 228-256. [CrossRef]

16. Sethurajan, M.; Hullebusch, E.D.V.; Fontana, D.; Akcil, A.; Deveci, H.; Batinic, B.; Leal, J.P.; Gasche, T.A.; Kucuker, M.A.; Kuchta, K.; et al. Recent advances on hydrometallurgical recovery of critical and precious elements from end of life electronic wastes-A review. Crit. Rev. Environ. Sci. Technol. 2019, 49, 212-275. [CrossRef]

17. Hennebel, T.; Boon, N.; Maes, S.; Lenz, M. Biotechnologies for critical raw material recovery from primary and secondary sources: R\&D priorities and future perspectives. New Biotechnol. 2015, 32, 121-127.

18. Murakami, H.; Nishihama, S.; Yoshizuka, K. Separation and recovery of gold from waste LED using ion exchange method. Hydrometallurgy 2015, 157, 194-198. [CrossRef]

19. Tan, Q.; Li, J.; Zeng, X. Rare Earth Elements Recovery from Waste Fluorescent Lamps: A Review. Crit. Rev. Environ. Sci. Technol. 2015, 45, 749-776. [CrossRef]

20. Gorewoda, T.; Eschen, M.; Charasinska, J.; Knapik, M.; Kozlowicz, S.; Anyszkiewicz, J.; Jadwinski, M.; Potempa, M.; Gawliczek, M.; Chmielarz, A.; et al. Determination of metals' content in components mounted on printed circuit boards from end-of-life mobile phones. Recycling 2020, 5, 20. [CrossRef]

21. Monneron-Enaud, B.; Wiche, O.; Schlömann, M. Biodismantling, a Novel Application of Bioleaching in Recycling of Electronic Wastes. Recycling 2020, 5, 22. [CrossRef]

22. Ueberschaar, M.; Schlummer, M.; Jalalpoor, D.; Kaup, N.; Rotter, V.S. Potential and Recycling Strategies for LCD Panels from WEEE. Recycling 2017, 2, 7. [CrossRef]

23. Abalansa, S.; el Mahrad, B.; Icely, J.; Newton, A. Electronic Waste, an Environmental Problem Exported to Developing Countries: The GOOD, the BAD and the UGLY. Sustainability 2021, 13, 5302. [CrossRef]

24. Cesaro, A.; Belgiorno, V.; Vaccari, M.; Jandric, A.; Chung, T.D.; Dias, M.I.; Hursthouse, A.; Salhofer, S. A device-specific prioritization strategy based on the potential for harm to human health in informal WEEE recycling. Environ. Sci. Pollut. Res. 2018, 25, 683-692. [CrossRef] [PubMed]

25. Daum, K.; Stoler, J.; Grant, R.J. Toward a more sustainable trajectory for e-waste policy: A review of a decade of e-waste research in Accra, Ghana. Int. J. Environ. Res. Public Health 2017, 14, 135. [CrossRef] [PubMed]

26. Islam, A.; Ahmed, T.; Awual, M.R.; Rahman, A.; Sultana, M.; Aziz, A.A.; Monir, M.U.; Teo, S.H.; Hasan, M. Advances in sustainable approaches to recover metals from e-waste-A review. J. Clean. Prod. 2020, 244, 118815. [CrossRef]

27. Wang, K.; Qian, J.; Liu, L. Understanding environmental pollutions of informal e-waste clustering in global south via multi-scalar regulatory frameworks: A case study of Guiyu Town, China. Int. J. Environ. Res. Public Health 2020, 17, 2802. [CrossRef] [PubMed]

28. Ceballos, D.; Dong, Z.; Frank, M. Formal E-Recycling: The Complexity of Solving the E-Waste Problem Worldwide. Hoffman Program on Chemicals and Health. 26 August 2016. Available online: https:/ / sites.sph.harvard.edu/hoffman-program/2016/0 8/26/formal-e-recycling-the-complexity-of-solving-the-e-waste-problem-worldwide/ (accessed on 22 July 2021).

29. Grant, K.; Goldizen, F.C.; Sly, P.D.; Brune, M.N.; Neira, M.; Van, D.B.M.; Norman, R.E. Health consequences of exposure to e-waste: A systematic review. Lancet Glob. Health 2013, 1, 350-361. [CrossRef]

30. Julander, A.; Lundgren, L.; Skare, L.; Grander, M.; Palm, B.; Vahter, M.; Liden, C. Formal recycling of e-waste leads to increased exposure to toxic metals: AN occupational exposure study from Sweden. Environ. Int. 2014, 73, 243-251. [CrossRef]

31. Xu, R.; Zheng, X.; Lin, Y.; Lin, C.; Guo, Y.; Huo, X. Assessment of dust trace elements in an e-waste recycling area and related children's health risks. Sci. Total Environ. 2021, 791, 148154. [CrossRef]

32. Rautela, R.; Arya, S.; Vishwakarma, S.; Lee, J.; Kim, K.H.; Kumar, S. E-waste management and its effects on the environment and human health. Sci. Total Environ. 2021, 773, 145623. [CrossRef]

33. Shahady, T.; Boniface, H. Water quality management through community engagement in Costa Rica. J. Environ. Stud. Sci. 2018, 8, 488-502. [CrossRef]

34. Charette, A.T.; Collins, M.B.; Mirowsky, J.E. Assessing residential socioeconomic factors associated with pollutant releases using EPA's Toxic Release Inventory. J. Environ. Stud. Sci. 2021, 11, 247-257. [CrossRef]

35. Adeola, F.O. WEEE generation and the consequences of its improper disposal. In Waste Electrical and Electronic Equipment Recycling; Woodhead Publishing: Cambrige, UK, 2018; pp. 13-31.

36. Jaiswal, A.; Samuel, C.; Patel, B.S.; Kumar, M. Go Green with WEEE: Eco-friendly Approach for Handling E-waste. Procedia Comput. Sci. 2015, 46, 1317-1324. [CrossRef] 
37. Fang, C.C. The case for environmental advocacy. J. Environ. Stud. Sci. 2021, 11, 169-172. [CrossRef] [PubMed]

38. Lawal, S. Nigeria Has Become an E-Waste Dumpsite for Europe, US and Asia. TRT World 2019. Available online: www.trtworld. com (accessed on 23 November 2021).

39. Charles, R.G. Assessment and Exploitation of the Inherent Value of Waste Electrical and Electronic Equipment (WEEE) for Circular Economy. Ph.D. Thesis, Swansea University, Wales, UK, 2018.

40. ILO. Tackling Informality in E-Waste Management: The Potential of Cooperative Enterprises; International Labour Organization: Geneva, Switzerland, 2014.

41. Işıldar, A.; Van, H.E.D.; Lenz, M.; Du, L.G.; Maria, A.; Cesaro, A.; Panda, S.; Akcil, A.; Kucuker, M.A.; Kuchta, K. Biotechnological strategies for the recovery of valuable and critical raw materials from waste electrical and electronic equipment (WEEE)-A review. J. Hazard. Mater. 2019, 362, 467-481. [CrossRef]

42. Ndunda, H.K.; Ambole, L.A. IRS-2018-8 Product-Service Systems Design for E-Waste Management: A Case Study of Waste Electrical and Electronic Equipment Centre in Nairobi County. In Innovation Research Symposium; School of Arts and Design, University of Nairobi: Nairobi, Kenya, 2018; pp. 73-81.

43. Gervich, C.D.; Briere, C.; Lopez, N.; Eudene, J.; Evans, C.; Fonzone, J.; Barbencena, R.O.; Witney, A.; Hastings, E.; Fernandez, A. Toxic Release! The role of educational games in teaching and learning about hazardous pollution. J. Environ. Stud. Sci. 2015, 6, 589-596. [CrossRef]

44. Okorhi, J.O.; Amadi-Echendu, J.E.; Aderemi, H.O.; Uhunmwangho, R.; Agbatah, O.B. Solving the waste electrical and electronic equipment problem: Socio-economic assessment on sustainable e-waste management in South Eastern Nigeria. Int. J. Environ. Technol. Manag. 2017, 20, 300-320. [CrossRef]

45. Richmond, M. Toxic chemicals: Environmental impact, regulation, controversy, and education: Editor's introduction. J. Environ. Stud. Sci. 2016, 6, 541-542. [CrossRef]

46. Bimir, M.N. Revisiting e-waste management practices in selected African countries. J. Air Waste Manag. Assoc. 2020, 70, 659-669. [CrossRef]

47. Ilankoon, I.; Ghorbani, Y.; Chong, M.N.; Herath, G.; Moyo, T.; Petersen, J. E-waste in the international context-A review of trade flows, regulations, hazards, waste management strategies and technologies for value recovery. J. Waste Manag. 2018, 82, 258-275. [CrossRef]

48. Mihai, F.; Gnoni, M.-G.; Meidiana, C.; Ezeah, C.; Elia, V. Waste electrical and electronic equipment (WEEE): Flows, quantities and management, a global scenario. Electron. Waste Manag. Treat. Technol. 2019, 1-34. [CrossRef]

49. Ogbuanya, T.C.; Afeez, Y.S. Advancing Electronic Waste Management Techniques among Electrical/Electronic Technicians' Workshops for Sustainable Healthy Society. Insights Min. Sci. Technol. 2019, 1, 90-104.

50. George, F.; Mapa, M.T.; Dinggai, S.A. IOP CoPreliminary Study on Waste Electrical and Electronic Equipment (WEEE) Management by Households in the Kota Kinabalu City. In Proceedings of the IOP Conference Series: Earth and Environmental Science, Langkawi, Malaysia, 3-4 December 2019; pp. 1-10.

51. Arya, S.; Gupta, A.; Bhardwaj, A. Electronic Waste Management Approaches-A Pilot Study in Northern Indian States. Int. J. Waste Resour. 2018, 8, 1-5. [CrossRef]

52. Yang, H.; Ma, M.; Thompson, J.R.; Flower, R.J. Waste management, informal recycling, environmental pollution and public health. J. Epidemiol. Community Health 2018, 72, 237-243. [CrossRef]

53. Alabi, R.A.; Wohlmuth, K. The Case of Sustainable Management of Waste in Germany (and Bremen) and Practical Lessons for Nigeria (and Lagos); University of Bremen: Bremen, Germany, 2019.

54. Deranek, K.; Chopra, S.; Mosher, G.A. Lean Adoption in a Small and Medium Enterprise: Model Validation. Manag. Appl. Eng. J. Technol. 2017, 33, 1-13.

55. Wee, H.M.; Wu, S. Lean supply chain and its effect on product cost and quality: A case study on Ford Motor Company. Supply Chain Manag. Int. J. 2009, 14, 335-341. [CrossRef]

56. Rever. Lean Safety-Improve Workplace Safety with Lean Principles. Rever Team. 22 March 2020. Available online: https: // reverscore.com/lean-safety/ (accessed on 28 May 2020).

57. Hamja, A.; Hossain, A.; Maalouf, M.M.; Hasle, P. A review paper on Lean and Occupational Health and Safety (OHS) in RMG industry. In Proceedings of the International Conference on Mechanical Engineering and Renewable Energy, Chittagong, Bangladash, 18-20 December 2017; pp. 1-5.

58. Alkhoraif, A.; Rashid, H.; McLaughlin, P. Lean implementation in small and medium enterprises: Literature review. Oper. Res. Perspect. 2019, 6, 1-19. [CrossRef]

59. McKinney, P.; Scalia, S. Just in Time Inventory: Definition, Advantages \& Examples. Study.com. 2019. Available online: https:/ / study.com/academy/lesson/just-in-time-inventory-definition-advantages-examples.html (accessed on 22 August 2020).

60. Chan, A. The Benefits of the Just-in-Time Approach. Unleashed. 2017. Available online: https://www.unleashedsoftware.com/ blog/benefits-jit-system-approach (accessed on 22 August 2020).

61. Wu, H.; Dong, X.; Wang, Q. New principle of busbar protection based on a fundamental frequency polarity comparison. PLoS ONE 2019, 14, e0213308. [CrossRef]

62. Singh, G.; Ahuja, I.S. Just-in-time manufacturing: Literature review and directions. Int. J. Bus. Contin. Risk Manag. 2012, 3, 57. [CrossRef] 
63. Davies, J. How to Improve Productivity with Just-In-Time by Toyota. Winman. 22 August 2020. Available online: https: / / www.winman.com/blog/how-to-improve-productivity-with-just-in-time-by-toyota (accessed on 23 August 2020).

64. Kivunja, C.; Kuyini, A.B. Understanding and Applying Research Paradigms in Educational Contexts. Int. J. High. Educ. 2017, 6, 26-41. [CrossRef]

65. Ragab, M.A.; Arisha, A. Research Methodology in Business: A Starter's Guide. Manag. Organ. Stud. 2017, 5, 1-24. [CrossRef]

66. Evans, C.; Lewis, J. Analysing Semi-Structured Interviews Using Thematic Analysis: Exploring Voluntary Civic Participation among Adults; SAGE Publications, Ltd.: Thousand Oaks, CA, USA, 2018; pp. 1-3.

67. Caulfield, J. How to Do Thematic Analysis | A Step-by-Step Guide \& Examples. Scribbr. 26 September 2019. Available online: https:/ / www.scribbr.com/methodology/thematic-analysis/ (accessed on 22 May 2020).

68. Nowell, L.S.; Norris, J.M.; White, D.E.; Moules, N.J. Thematic Analysis: Striving to Meet the Trustworthiness Criteria. Int. J. Qual. Methods 2017, 16, 1-13. [CrossRef]

69. Elliott, V. Thinking about the Coding Process in Qualitative Data Analysis. Qual. Rep. 2018, 23, 2850-2861. [CrossRef]

70. Poucher, Z.A.; Tamminen, K.A.; Caron, J.G.; Sweet, S.N. Thinking through and designing qualitative research studies: A focused mapping review of 30 years of qualitative research in sport psychology. Int. Rev. Sport Exerc. Psychol. 2020, 13, 163-186. [CrossRef]

71. Vaismoradi, M.; Snelgrove, S. Theme in qualitative content analysis and thematic analysis. FQS Forum Qual. Soc. Res. 2019, 20, 1-14. [CrossRef]

72. Szedlak, C.; Smith, M.J.; Day, M.C.; Greenlees, I.A. Effective behaviours of strength and conditioning coaches as perceived by athletes. Int. J. Sports Sci. Coach. 2015, 10, 967-984. [CrossRef]

73. Lydall, M.; Nyanjowa, W.; James, Y. Mapping South Africa's Waste Electrical and Electronic Equipment (WEEE) Dismantling, PreProcessing and Processing Technology Landscape; Mintek Private Bag X3015: Randburg, South Africa, 2017.

74. Baldé, C.P.; Forti, V.; Gray, V.; Kuehr, R.; Stegmann, P. The Global E-Waste Monitor 2017: Quantities, Flows, and Resources; United Nations University (UNU): Bonn, Germany; International Telecommunication Union (ITU): Geneva, Switzerland; International Solid Waste Association (ISWA): Vienna, Austria, 2017.

75. Fischer, D.; Seidu, F.; Yang, J.; Felten, M.K.; Garus, C.; Kraus, T.; Fobil, J.N.; Kaifie, A. Health Consequences for E-Waste Workers and Bystanders-A Comparative Cross-Sectional Study. Int. J. Environ. Res. Public Health 2020, 17, 1534. [CrossRef]

76. Lenz, K.; Afoblikame, R.; Kacher, Y.S.; Kotoe, L.; Schluep, M.; Smith, E.; Schroder, P.; Valdivia, S. E-Waste Training Manual; Deutsche Gesellschaft für Internationale Zusammenarbeit (GIZ) GmbH: Bonn, Germany, 2019.

77. Jain, A. Compendium of Technologies for the Recovery of Materials from WEEE E-Waste; United Nations Environment Programme, (UNEP): Nairobi, Kenya, 2017.

78. Manzouri, M.; Ab-Rahman, M.N.; Zain, C.R.C.M.; Jamsari, E.A. Increasing production and eliminating waste through lean tools and techniques for Halal food companies. Sustainability 2014, 6, 9179-9204. [CrossRef]

79. Cerra, J. Advantages and Disadvantages of Just-in-Time (JIT) Manufacturing. Planet Together. 23 May 2019. Available online: https:/ / www.planettogether.com/blog/advantages-and-disadvantages-of-just-in-time-jit-manufacturing (accessed on 8 December 2020). 